\title{
The Deadly Duo-A Combination of Allergy and Acute Coronary Syndrome A Case of Kounis Syndrome Type 1
}

\author{
Ramkumar Rajappan ${ }^{1}$, Bivin Wilson ${ }^{2}$, Priya Kubendiran², Rajpal K.Abhaichand ${ }^{3}$, Abhishek Kasha ${ }^{4}$ \\ ${ }^{1}$ Senior Medical Officer, ${ }^{2}$ Consultant Interventional cardiologist, ${ }^{3}$ Chairman and Consultant Interventional \\ Cardiologist, ${ }^{4}$ Cardiology Trainee, Department of Cardiology, GKNM Hospital, Coimbatore, India
}

\begin{abstract}
Kounis syndromewas first described by Kounis and Zavras in 1991, as the concurrent occurrence of acute coronary events with an allergic or a hypersensitivity response. Mast cell activation and release of inflammatory mediators have shown to induce coronary spasm, plaque erosion and even stent thrombosis. A 41 years old male, smoker was admitted with chest discomfort and features suggestive of myocardial infarction. His ECG showed ST elevation and T inversion in I, aVL. High sensitive troponin I was elevated and echocardiogram was normal. Four days ago, he had a history of redness and itching all over the body and was treated for allergic dermatitis. He had a family history of urticaria also. Coronary angiogram revealed no major flow limiting coronary artery disease. Kounis syndrome type 1 was diagnosed and he was discharged on oral steroids and cardiac drugs. We always have to think of Kounis syndrome when treating a young patient with allergy or anaphylaxis and concurrent acute coronary syndrome. Prompt recognition is important as treatment is significantly different.
\end{abstract}

Key Words: Allergic dermatitis,Kounis syndrome, Mast cells, Myocardial Infarction, allergic acute coronary syndrome.

\section{Case History}

A 41 years old male, who was a smoker for more than 10 years, developed chest discomfort and breathlessness at rest. His pulse rate was $66 / \mathrm{min}$, blood pressure-140/80 $\mathrm{mmHg}$, respiratory rate- $22 / \mathrm{min}$, and saturation of $98 \%$ in room air. His cardiovascular, respiratory, abdominal, and central nervous system examination were normal. His electrocardiogram showed sinus rhythm, with STelevation and $\mathrm{T}$ inversion in $\mathrm{I}, \mathrm{aVL}$ and tall $\mathrm{T}$ waves in chest leads (figure 1). His cardiac enzyme was elevated (high sensitive Troponin I -113 pg/ml).Echocardiogram showed no regional wall motion abnormality with adequate ventricular function. With the available evidence, he was diagnosed to have high lateral myocardial infarction with spontaneous recanalization.

He gave a history of redness and itching all over

\section{Corresponding Author:}

\section{Dr. Bivin Wilson, G.}

Kuppuswamy Naidu Memorial Hospital, Coimbatore, India.+919488161261, bivinwilson@gmail.com. the body, four days back. He was diagnosed as allergic dermatitis and was treated with IV antihistamines and steroids. His father and elder brother had a history of urticaria. Skin examination showed urticarial lesions over the anterior chest and back (figure 2). His IgE level was high-253 IU/ml. Serum C3,C4 were normal. Dyslipidemia(LDL-202 mg/dl, total cholesterol-258 mg/ dl) was present. He had polymorphonuclear leukocytosis. He was treated with standard acute coronary syndrome measures, along with IV steroids, antihistamines, and mast cell stabilizers.

Coronary angiogram was done which revealed no major flow-limiting coronary artery disease with grade III myocardial bridging in left anterior descending artery (Figures 3-5). He was later given per oral steroid in tapering dose, single antiplatelet, and statins. His urticarial skin lesionssubsequently improved. From thehistory, clinical examination, and relevant investigations, we diagnosed this, as a case of Kounis Syndrome type I. Because of the normal angiogram, he is probably having Type I Kounis syndrome with coronary spasm leading to myocardial infarction (MI) and enzyme elevation. 

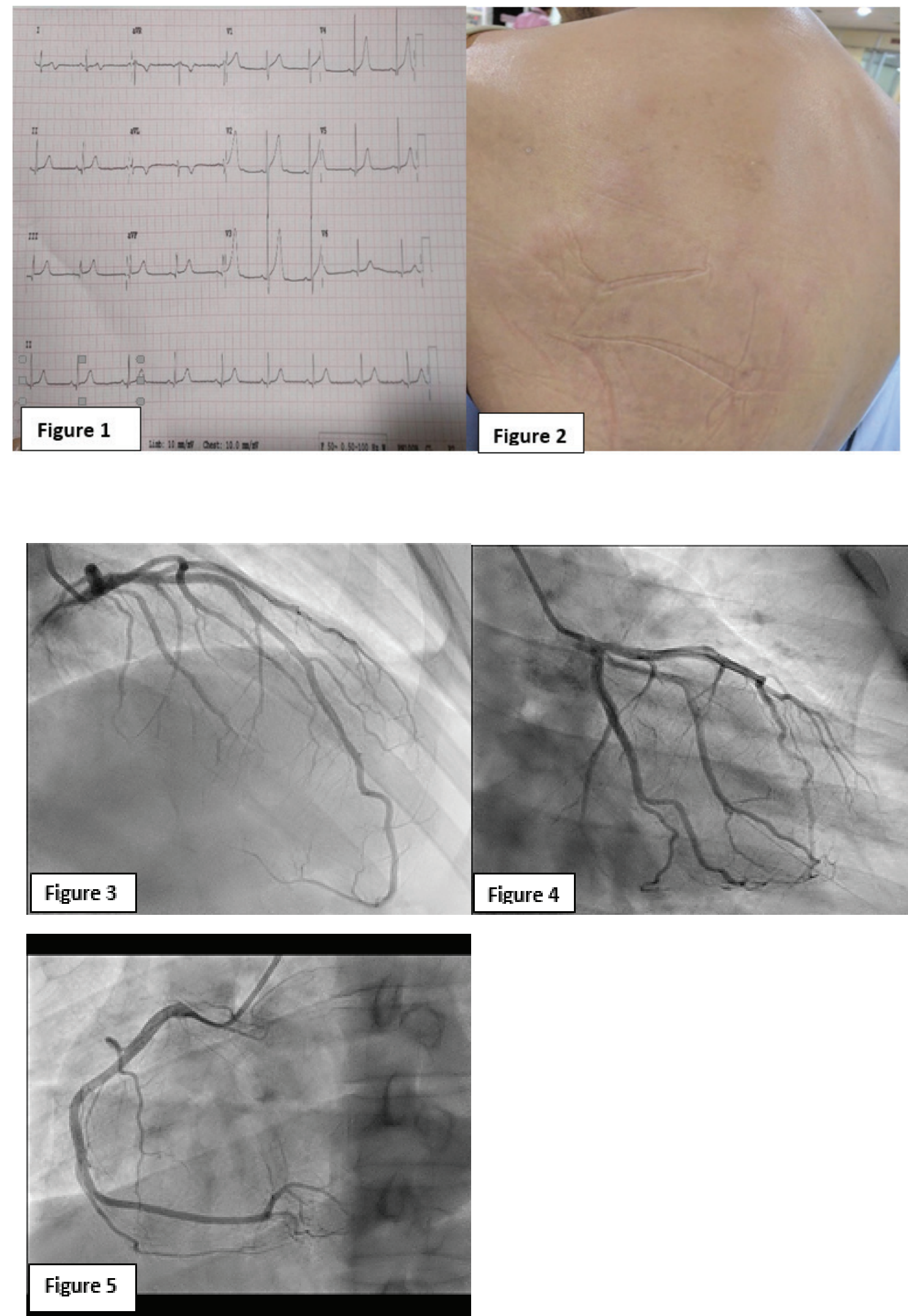

Figure 1-Electrocardiogram showing ST elevation of $1 \mathrm{~mm}$ and $\mathrm{T}$ inversion in $\mathrm{I}, \mathrm{VVL}$ and tall $\mathrm{T}$ waves in Chest leads. Figure 2- urticarial lesions. Figure 3 to 5-Coronary angiogram showing normal coronaries. 


\section{Discussion}

Kounis syndrome was first described by Kounis and Zavras in $1991^{(1)}$, asthe concurrent occurrence of acute coronary events withan allergic or hypersensitivity response. The condition hasthree variants ${ }^{(2)}$, i.e. type 1 - coronary spasm;type 2 - coronary thrombosis; and type 3 -drug-eluting stent thrombosis. Management differs depending on the type. Inflammatory mediators are released mainlyfrom activated mast cells and via bidirectionalstimuli, macrophages, and T-lymphocytes. Activated mast cells accumulate in large numbers in the areas ofplaque erosion or rupture in patients sufferingfrom acute $\mathrm{MI}^{(3)}$.

- Type 1 variant comprises of patients with normal coronary arteries ${ }^{(4)}$ withoutpredisposing risk factors, in whom the acute release ofinflammatory mediators can induceeither coronary artery spasm without elevation of cardiac enzymesor coronary artery spasm progressing toacute MI with raisedcardiac enzymes and troponins.

- Type 2 variant includes patients with quiescent, preexisting atheromatous lesions, in whom inflammatory mediators can induce either coronary artery spasm or acute MI.

- Type 3 variant comprises of patients with coronarythrombosis (including stent thrombosis) and there is the presence of eosinophils and mast cells in the aspirated thrombus specimensstained with hematoxylineosin and Giemsarespectively.

Measurement of histamine, released by mast cell degranulationwithin

5 - 10 minutes is helpful, but remains elevated foronly $30-60$ minutes and therefore hasvery limited value. Serum tryptasehas been identified as a reliable marker ofanaphylaxis ${ }^{(5)}$. Adiagnosis of Kounis syndrome can still be made based on theclinical presentation, regardless of the documented laboratory evidence and treatment carriedout accordingly.

\section{Conclusion}

Ours is a case of Type I variant of Kounis syndrome, with normal coronary arteries in whom the allergic reaction has led to coronary artery spasm leading to myocardial infarction in D1 territory. Treatment with IV steroids, mast cell stabilizers and antihistamines has helped this patient. This syndrome isotherwise called as an allergic acute coronary syndrome.

\section{Conflict of Interest: Nil}

\section{Source of Funding: Self}

Ethical Clearance: Taken from Institutional Ethical Committee, GKNMH.

\section{References}

1. Kounis NG, Zavras GM. Histamine-induced coronary artery spasm: the concept of allergic angina. The British Journal of Clinical Practice. 1991;45(2):121-128.

2. Kounis NG. Coronary hypersensitivity disorder: the Kounis syndrome. Clinical Therapeutics. 2013;35(5):563-571.

3. J. Steffel, A.Akhmedov, H. Greutert, T. F. Luscher, and F. C. Tanner. "Histamine induces tissue factor expression". Circulation.Vol. 112, no. 3, pp. 341349, 2005.

4. L. L. Reber, J. D. Hernandez, and S. J. Galli. "The pathophysiology of anaphylaxis," Journal of Allergy and Clinical Immunology. Vol. 140, no. 2, pp. 335-34810, 2017.

5. Kounis NG, Mazarakis A, Tsigkas G. Kounis syndrome: a new twist on an old disease. Future Cardiology; 2011; 7(6):805-24. 